\title{
The Impact of New Energy Development on Energy Intensity and Economic Growth
}

\author{
Jing $\operatorname{Sun}^{1, \mathrm{a}}$ \\ ${ }^{1}$ No. 6388, Xihuan Road, Weicheng District, Weifang City, Shandong Province, Shandong Vocational College of Science and \\ Technology
}

\begin{abstract}
In recent years, new energy has been rapidly developed and applied. The development of new energy has promoted China's economic growth to a specific extent. The use of new energy has brought energy security to the development of the national economy. Based on the development trend of new energy at home and abroad, this paper analyses the impact of energy intensity and economic growth on the development of new energy. This article explores the relationship between China's new energy, energy intensity and economic development through comparative analysis at home and abroad. This article has a certain reference value for the adjustment of the national new energy industrial structure. This article also has a certain reference value for the construction of new energy development strategies and the control of carbon emissions.
\end{abstract}

\section{Introduction}

In the 21 st century, energy and environmental issues have become hot topics in people's lives. The large-scale exploitation of domestic energy materials has led to a severe shortage of reserves. People pay more and more attention to the development of new energy. To ensure the safety of new energy and ensure that it does not affect climate issues, we need to coordinate the relationship between new energy and various variables of economic growth. To ensure the smooth development of new energy development. The development of new energy is the key to achieving sustainable development. Sustainable development policies help to adjust energy resources, thereby changing the industrial structure and realizing the long-term development of the country.

\section{The status quo of new energy development at home and abroad}

\subsection{Development of new energy abroad}

Western developed countries regard the development of new energy as the most significant development strategy. They put new energy in an essential position of social and economic development. They believe that the development of new energy is an important pillar of energy intensity and economic growth. Some developed countries have formulated superior policies or preferential conditions to support the development of new energy. With the increasingly severe environmental problems, the development of new energy sources in various countries worldwide is in full swing.
Correspondingly, all countries have increased their investment in new energy development. The proportion of new energy used in various countries is also gradually increasing, such as the familiar wind energy. In the overall industrial structure of new energy, wind energy is a kind of clean energy. Wind energy technology is mature and has good development prospects. In recent years, the limiting factors of wind power generation technology have gradually decreased, thereby effectively improving the efficiency of wind power generation and also achieving an increase in power generation efficiency and total power generation. In the current new energy industry, solar power generation technology is relatively mature, so this technology is widely used daily. The efficiency of the everyday use of photovoltaic cells is gradually getting higher and higher, and the amount of power generation is also increasing year by year. For example, Japan, the United States and China have become emerging markets for photovoltaic cells. Three countries account for $30 \%$ of the world's installed capacity. Besides, biomass energy is a relatively new method. U.S. biomass energy technology is currently at the world's highest level. Besides, geothermal energy is also a rich energy reserve, currently mainly used in Japan. From worldwide publications, the current development and development of new energy is showing a diversified development trend.

Table 1. Comparative analysis of new energy access levels at home and abroad.

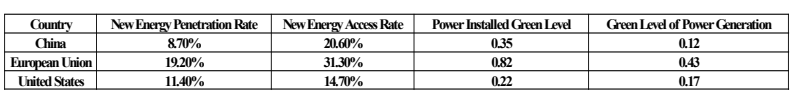

Table 1 shows the comparison of the evaluation indicators of China, the European Union and the United 
States' new energy access level in 2019. According to the data in the table, the following conclusions can be drawn: First, the EU has the highest level of new energy access and is in a highest position in the world. In terms of new energy penetration rate, new energy access rate, green level of installed power supply and green level of power generation, the EU leads China and the United States.

Second, China's new energy access level is the same as that of the United States on the whole and is at the advanced level in the world. China leads the United States in terms of new energy access rate and green level of power installed capacity. Still, the United States leads China in terms of new energy penetration rate and green level of power generation. Although the installed capacity of new energy in the United States is lower than that in China, the United States has good wind and solar resources. The amount of new energy generation is relatively high. While promoting the rapid development of new energy installed capacity, China still needs to further increase the level of new energy power generation. Besides, affected by the power structure, China's thermal power is still in the dominant position of power generation, and the amount of thermal power generation is relatively high, so the green level of power generation is relatively low.

\subsection{Development of China's new energy industry}

\subsubsection{The government supports the development of new energy}

The Chinese government is committed to the development and development of new energy. The government reduces environmental pollution by reducing its dependence on oil imports. At the same time, to improve China's industrial structure, the state has introduced a series of policies and preferential measures to vigorously develop the new energy industry.

\subsubsection{Increased investment in new energy development}

After 2016, China, as the country with the most enormous scale of new energy development in the world, has ranked first in the world in terms of investment in the new energy industry. The main investment channels are the development and development of new energy sources such as hydropower, wind power, solar energy, biomass energy and nuclear energy. From the perspective of the market size of the new energy industry from 2010 to 2017, the market size of China's new energy industry has reached around US $\$ 400$ billion. According to expert assessments, China's future investment in the new energy industry will reach 5 trillion yuan. In recent years, China's demand for new automotive energy, biomass energy and solar energy has increased day by day. Although wind energy is rich in resources, its development has been slow. Therefore, many experts believe that the use of abandoned wind energy must be solved first. Then energy management and scientific planning must be strengthened according to the current research status of new energy. It is necessary to promote the balanced development of new energy, and at the same time, cooperate with a sound government system and policy environment to truly incorporate the development and utilization of new energy into an important position in the national strategic plan.

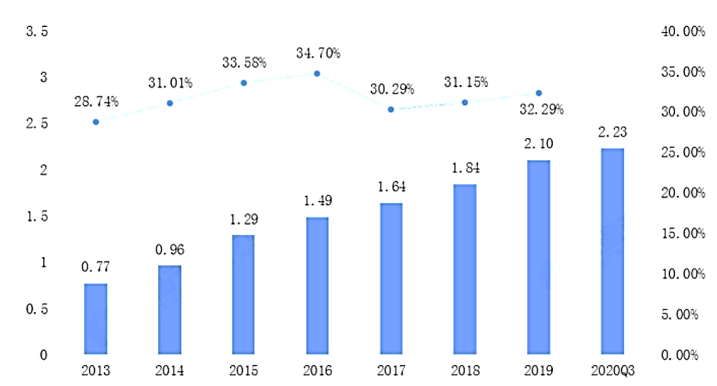

Figure 1. 2013-2020 China's cumulative grid-connected installed capacity of wind power and its global share (unit: 100 million kilowatts, \%).

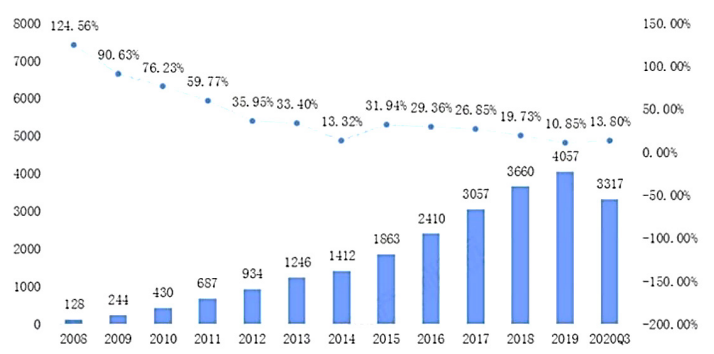

Figure 2. China's wind power generation capacity from 2008 to 2020 (unit: 100 million $\mathrm{kWh}, \%$ ).

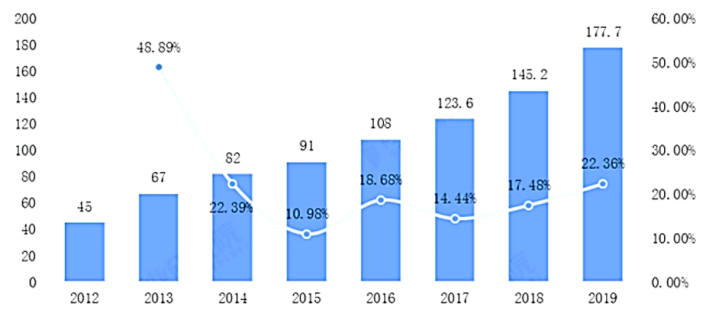

Figure 3. 2012-2019 China's wind power operation and maintenance market scale (unit: 100 million yuan, \%).

\subsubsection{Development of the industrial chain is lagging}

China is a country with vast territory and rich wind energy resources. Wind power is a leader in China's new energy development. Moreover, the industrial chain of wind power generation has initially taken shape. In China's new energy development, solar energy has developed rapidly. Among them, the quality of photovoltaic cells is significantly higher than other cells. However, the development of photovoltaic cells has been hindered by trade protectionism, which has led to Chinese photovoltaic companies not entering the European and American markets.

Compared with foreign countries, China's new energy development and utilization industrial chain is relatively lagging. The technology and management of new energy are also in urgent need of improvement. In 
using new energy, it is difficult for China to make breakthroughs in new energy technology. Although more supportive and preferential policies have been introduced, they have little effect on new energy development.

\section{The impact of new energy development on energy intensity and economic growth}

The development and utilization of new energy can solve the current shortage of energy and the environmental pollution caused by it. New energy can alleviate the current situation of energy shortage and is an important way to contribute to China's low-carbon economy. In exploring using new energy, the evolution system of energy saving and emission reduction can influence the intensity of new energy and economic growth. Analysis of new energy, energy intensity and economic growth shows that new energy has a more significant impact on energy intensity in terms of economic input. If the economic investment is too large, it will significantly hinder the development of the new energy economy. If the comprehensive investment in new energy is increased, energy intensity can be better reduced. When the overall investment increases, it starts to hinder economic development. However, with the further development of the system, when new energy development is ripe, it will significantly promote economic growth.

Energy intensity represents the amount consumed by the output value, sector, region or industry. The energy intensity of new energy compares domestic total primary energy use and final energy use with GDP. It can measure the country's efficiency in the use of new energy. Energy intensity is affected by various factors, such as economic structure and technical level. Energy intensity is also an important indicator in national economic and technological measures, energy level, energy structure and energy security.

There have been related studies on the relationship between the energy industry and economic growth for a long time. Germany's Kreef and Weilsk used the SIM solution to make a detailed analysis of the data on energy consumption and economic growth in Germany. The analysis results show that when Germany's gross national product increases, energy consumption also increases. Other countries have used their research methods to analyze their energy consumption and economic growth, and the results of the analysis are generally consistent. After breakthroughs in research on energy consumption and economic growth, China has also begun to study in this area. For example, the professional team formed by Zhang Jiayu and Zhao Qiang. They use co-integration and Granger causality testing methods for data analysis. Through the analysis of China's gross national product and total energy consumption over the years. The final analysis result is very close to the analysis and research results of foreign experts. That is to say, the development of new energy has a positive correlation with energy consumption and economic growth in a certain period.
China's energy consumption and economic growth are in equilibrium with each other. At present, global energy is being developed and consumed on a large scale. In today's increasingly tight energy, experts have turned their research directions to analysis energy structure and energy efficiency. For example, Zhang Chao's research team selected data on China's energy consumption and economic growth from 1990 to 2000 for analysis. Through calculations, the changes in China's energy consumption intensity and energy efficiency were obtained. China has gradually matured in terms of new energy development. China has made breakthrough progress in energy intensity and economic growth. It is very necessary to correctly clarify the relationship between energy intensity and economic growth in the development of new energy.

New energy has the characteristics of being clean and renewable, and it is an effective measure to alleviate the shortage of conventional energy. New energy is friendly energy that is beneficial to the development of society. The vigorous development and application of new energy can significantly reduce energy costs and improve economic benefits. Therefore, the reduction of energy intensity can promote the development of new energy.

Economic growth promotes the development of new energy. Investment in new energy research is significantly affected by economic development. Especially in the initial stage of economic development, the economic growth rate is controlled and the growth rate is low, so the development of new energy is slow. With the rapid growth of China's economy, there has been a severe shortage of traditional energy sources. At this time, new energy has accelerated the pace of development. Economic growth has been severely restricted in terms of the lack of traditional energy sources. The widespread application of new energy has alleviated the current situation of energy shortage. New energy has improved the utilization rate of energy consumption, saved consumption costs, and stimulated the development of enterprises. In economic development, new energy has become the most critical growth point.

As the time for new energy development is not long, its research data has limitations. Due to the choice of research methods and the particularity of the research area, the impact of energy development on energy intensity and economic growth may be more complex, requiring follow-up and continuous research and discussion.

\section{New energy development strategies based on energy intensity and economic growth}

\subsection{Adopt a moderate new energy development strategy}

The development model of new energy is different from non-renewable resources. The development of new 
energy lies in the development and application of new technologies. However, traditional fossil energy is usually used on a large scale, which cannot avoid its severe pollution to the environment. The main pollutant of traditional fossil energy is carbon emissions. Moreover, the reserves of fossil energy are decreasing year by year, and there is a foreseeable energy crisis. Therefore, every country must find a new way of developing its own energy security and stability.

As the second-largest economy globally, China needs to fully consider the impact of new energy development on energy intensity and economic growth when formulating new energy development strategies. China should choose to adopt a moderate new energy development strategy, not too radical.

\subsection{Control the investment intensity of new energy}

Controlling new energy development and investment can effectively control energy intensity. If the economic investment is too large, it will hinder economic development to a certain extent. However, energy intensity can be reduced by investing in energy conservation and weakening the evaluation system. With the increasing of comprehensive investment, new energy will gradually mature, thereby promoting economic development more effectively.

\subsection{Deepen the adjustment of industrial structure}

New energy has the characteristics of being clean and renewable. New energy can alleviate the shortage of resources in various countries and protect the environment. Due to the low energy density of new energy sources, the development of new energy sources requires a large plant space. Distributed energy utilization needs to be realized through multiple uses, so the development of new energy requires reasonable planning and opening up the necessary space.

The application of new energy sources can reduce energy intensity. Energy intensity can measure the unit energy consumption of each output value. After the economic development reached a certain level, energy consumption continued to grow, energy supply began to be insufficient, and energy costs increased. In order to reduce costs, the industrial structure gradually moved closer to low energy intensity. And because of the increasing proportion of new energy in the total energy. Adjusting the industrial structure and increasing the application of new energy can significantly reduce energy consumption and drive economic income.

\subsection{Give play to the stimulating effect of new energy on economic growth}

With the continuous economic development of countries around the world, their demand for energy continues to increase. The large-scale development of traditional energy sources has caused severe environmental pollution. Fossil energy is drying up, and energy shortages have begun to restrict the country's economic growth. At present, all countries have begun to devote themselves to the development of new energy. In the short term, the development of new energy requires a lot of workforce and material resources. However, when new energy is mature, it will have a long-term positive effect of stably promoting economic growth.

Since new energy is lower in cost and reusable than traditional energy, its application in enterprise production is more extensive, providing a more environmentally friendly and efficient energy guarantee for sustainable economic development.

\section{Conclusion}

Comprehensive investment in new energy can well reduce energy intensity. Through the development and utilization of new energy sources, China's current energy consumption structure can be continuously improved. Real energy saving and emission reduction effects can be achieved by avoiding the use of high-emission fossil energy. The new energy industry is becoming a strategic emerging industry with more viable and potential talents. Its development can promote the upgrading of China's industrial structure and promote the development of a low-carbon economy. It is of great significance to study the impact of new energy development on energy intensity and economic growth, as well as to formulate new energy development strategies and control carbon emissions.

\section{References}

1. Zaenhar Duman, Sun Hui, Wang Shixuan. Research on the relationship between the scale and distribution of new energy industrial clusters and the level of regional economic growth. Science and Technology Management Research, 2020, 40(13): 78-84.

2. Ma Qianli, Li Qian. An Empirical Study on the Relationship between New Energy, Traditional Energy and China's Economic Growth. Resources and Industry, 2019, 21(2): 85-94.

3. Luo Chunbao. Research on the impact of new energy development on economic growth. Economic and Trade Practice, 2018(12): 100.

4. Liu Kai, Zhang Jialuan, Zhao Jingbo. The impact of new energy development on energy intensity and economic growth. China Chemical Industry Trade, 2018, 10(23): 3 .

5. Ai Chuanlong. The impact of new energy development on energy intensity and economic growth. Architectural Engineering Technology and Design, 2018(8): 4761.

6. Liang Yuelian. The impact of new energy development on economic growth. Management Scientist, 2018(10):117-118. 